that of the divisions which deal with higher degrees ; this frees research workers whose chief interest is the multiplication of published papers from work which will not lead to their academic advancement, but has the unfortunate effect of making the others, whose job is teaching rather than research, feel somewhat second-class.

Dr. C. Gordon dealt with a course in social biology which he gives to social science students at Edinburgh; this is complementary to one in anatomy and physiology given by a physician. The biology is academic and vocational and includes topies such as man's place in the animal kingdom, the effects of heredity and environment, and some discussion of physiology and vital statistics. The students take an examination at the end of the course, and their answers are on the whole well written but show no evidence of any ability to interpret data. This is partly because the students are frightened of mathematics, but may also be due to the absence of any practical work, which the scientists have not yet been able to induce the board of studies to impose.

In the subsequent discussion, a number of speakers said that they could give a better education if they had students for four years instead of three; but there was no general agreement on the meaning of a fourth year or on what to do with it. For some, it seemed to mean ignoring what the students had done at school or teaching them again what they had already had the opportunity of learning there; for others it meant the possibility of lengthening and strengthening the course for an honours degree. The sense of the meeting was probably that it is a good thing to have a specialist staff to teach science to arts students; but that its members should also take part in straightforward research, and that some form of practical work is desirable.

In the afternoon Prof. Gemmell took the chair, and the conference heard three professors at North Staffordshire say how useful his biology course was for their students. Prof. S. Finer (social science) found its advantage to be that it taught them the background of knowledge of human ecology necessary for their practical work; Prof. W. C. Stewart (education) welcomed it for its aid in the understanding of child development; and Prof. J. Blake (history) liked its broadening of outlook and its development of a different aspect of truth from those with which the historian and philosopher deal. In the absence through illness of Mr. L. J. F. Brimble, Mr. W. B. Yapp (Birmingham) gave the only other set paper in this session, which had the title "Biology for Arts Students-Is it worthwhile ?" He suggested that in order for such courses to be justified, there had to be a successful solution of the problem of language, careful selection of topics which are wide in scope but deep in the demands which they make on the students' understanding, and even more careful selection of the teacher. Referring to the theory of organic evolution as probably the best single topic, both on theoretical grounds and in practice, he said that those who taught it to arts students should have a wide background of knowledge and in particular ought to have read "The Origin of Species". This divided the audience, or at least the vocal part of it, fairly evenly into those who had read the book and agreed with the speaker, and those who had not and thought it unnecessary to do so. In the rest of the discussion Prof. T. A. Bennet-Clark (King's College, London) voiced the disappointment of many of the biologists when he said that the three Keele speakers had all spoken chiefly of the value of biology on vocational grounds.

The final session, with Prof. O. E. Lowenstein in the chair, was on "Biology in a General Science Education". Prof. Bennet-Clark defended it as suitable for third-class and pass-degree men who would enter commerce, and felt that a training in science gives a better education, in $\mathrm{A}$. N. Whitehead's sense of "a habitual vision of greatness", than is now possible for the humanities. Prof. F. W. R. Brambell (Bangor) put the case against general science by arguing for the virtues of specialization on educational grounds. He recommended oppor. tunism in the choice of advanced courses, and the pursuit of them to the forefront of knowledge according to the interests of the staff available. Among points raised in the general discussion were the difficulty that early study of the basic sciences often lays down special interests at school (Dr. Gordon); the need for courses not leading to a professional career in biology (Dr. Hutchens); the advantage of an encyclopædic knowledge (Prof. Lowenstein); the importance of knowing when one is ignorant (Mrs. Riddiford); and the value of a biological training in teaching one to deal with complex situations. There seemed in the end to be a greater measure of agreement between the two principal speakers than at first appeared. Both wanted as much specialization as possible for those who could profit from it, and both held that biology had more to offer than its mere vocational value for those who would use it in after life. One of the most pleasing aspects of the conference was the general feeling that a university training in biology can be one of the best preparations for entry to those careers in administration and leadership for which we have not yet designed precise undergraduate courses. Biology, in fact, might well take part of the place so long occupied by the classics but for which they are no longer fitted. One would like to see a full and reasoned statement of this view, which was implicit rather than openly said in much that passed at the conference.

W. B. YAPP

\section{GASEOUS ELECTRONICS CONFERENCE IN NEW YORK}

$T$ HE Gaseous Electronics Conference has now become an annual meeting in the United States which is greatly looked forward to by all those interested in the subject. The 1954 Conference was sponsored by the Division of Electron Physics of the American Physical Society, and the host institution was the College of Engineering of New York Univer. sity, which is celebrating its centenary. The meetings were held in New York City during October 14-16, and were attended by about 240 members from all over the United States and Canada. More than a third of the forty-five papers (forty-one contributed and four invited) came from universities, the rest coming from the great industrial laboratories and government establishments, representing in all twenty-seven different organizations. Members of the Conference were entertained at a banquet at which the guest speakers were Dr. T. E. Allibone, of Associated Electrical Industries, Aldermaston, who described current work in England on gaseous electronics, and Dr. W. Finkelnburg, of Siemens. Schuckert, Erlangen, who described present-day 
German work in this field. The chairman of the Committee of the Conference was Dr. W. P. Allis, of the Massachusetts Institute of Technology, and Dr. L. H. Fisher, of New York University, as secretary, was responsible for the excellent Conference arrangements.

A very wide field was covered in the papers and it is not possible in this brief report to describe the material in any detail : their subject-matters ranged from atomic cross-sections to the properties of complicated statistical assemblies such as the hightemperature arc. Of late years much work has been done in improving modern vacuum techniques and in the preparation of pure gases and of clean surfaces, and this has led to the re-evaluation of some fundamental ionization and collision data. Among such papers were those of W. H. Hickman and R. E. Fox (Westinghouse) on negative-ion formation using low $(0 \cdot 1-\mathrm{eV}$.) mono-energetic electrons, the narrow capture process yielding information about the behaviour of such electron beams, and that of $\mathrm{E}$. Gerjuoy (Pittsburg) and S. Stein (Westinghouse) discussing theoretical work on rotational excitations by slow electrons. L. M. Branscomb (Bureau of Standards) described measurements of the photodetachment cross-section for the hydrogen atorn, obtaining a result within 10 per cent of that calculated by Chandrasekhar. N. Wainfan, W. C. Walker and G. L. Weissler (Southern California) reported determinations of cross-sections for photoionization of carbon dioxide, argon and the hydrogen and water molecules in the wave-length range 473$1100 \mathrm{~A}$., and of photoelectric yields in the vacuum ultra-violet. The atomic absorption cross-section of atomic nitrogen found by A. W. Ehler and G. L. Weissler agrees with that calculated by Bates. D. J. Rose (Bell Laboratories) reported recent determina. tions of Townsend's $\alpha$ in hydrogen over the range $20<Z / p<1,000$ V./cm. mm. mercury, assessing disagreements between previous determinations. H. D. Hagstrum (Bell Laboratories) described determinations of the secondary emission of electrons from surfaces either atomically clean or contaminated by a monomolecular gas layer. With clean surfaces $\gamma_{\max }$. for $\mathrm{He}^{+}$is found to be $\sim \mathbf{0 . 2}$ and largely independent of ion energy; but for contaminated surfaces $\gamma$ increases with ion energy and may become as high as unity. F. Keywell (Bell Laboratories) discussed high-vacuum sputtering. R. N. Varney (Washington) reported work on diffusion, and A. V. Phelps (Westinghouse) described the diffusion and volume-loss coefficients of helium metastable atoms and molecules; and the life-time of metastable mercury molecules was discussed by C. G. Matland and A. O. McCoubrey (Westinghouse).

Another group of papers dealt with the physics of plasma. Plasma oscillations were considered by J. E. Drummond and L. Wilcox (Sylvania); fluctuations in crossed electric and magnetic fields by $\mathrm{H}$. W. Batten (Michigan); travelling striations by N. L. Oleson (U.S. Naval Postgraduate School); noise mechanism by M. I. Skolnik (Johns Hopkins); aspects of plasma resonance by $\mathbf{K}$. S. W. Champion and S. C. Brown, and a microwave study of positive ion collection using probes by G. J. Schulz and S. C. Brown (Massachusetts Institute of Technology); cumulative ionization processes in the helium positive column by L. S. Frost and A. V. Phelps (Westinghouse).

A number of papers dealt with properties of the electric arc. Low-voltage phenomena were discussed by E. O. Johnson (R.C.A.) and extreme temperature phenomena by W. Finkelnburg (Siemens-Schukert). Other aspects of discharge phenomena were described in a session which included an invited paper by $\mathrm{H}$. Margenau (Yale) on the effect of electrons on spectral lines emitted in a discharge, and papers on the cathode spot are by Robert St. John, J. G. Winans (Wisconsin) and by C. G. Smith (Raytheon). D.C. ares in a magnetic field were discussed by $L$. $P$. Winsor (Rensslaer) and T. H. Lee (General Electric), and R. W. Warren (California) reported measurements of electric fields in glow discharges.

A third of the programme was devoted to papers on electrical breakdown, and, in particular, to the ionization processes by which the ionization builds up on the application of electric fields.

Variation of mean free paths in discharges was considered by I. A. MacLennan and A. D. MacDonald (Dalhousie). Two papers on the influence of field emission on Paschen's law at high pressure and in vacuum phenomena breakdown were given by $\mathrm{L}$. $\mathrm{H}$. Germer, P. Kisliuk and W. S. Boyle (Bell Laboratories). The influence of molecular structure on the sparking potential of hydrocarbon gases was discussed by R. W. Crowe and J. C. Devins (General Electric). A paper by E. L. Huber (California) described work on corona breakdown in nitrogen and oxygen and mixtures, using $\alpha$-particle triggering. Further experimental evidence on the development of a Townsend avalanche preceding breakdown was given by H. W. Bandel (California) for air ; and for argon by M. Menes (Westinghouse), who suggested a process involving delayed photon emission. A session was devoted to a symposium of three invited papers on breakdown. A paper on the mechanism of uniform field static breakdown was given by $\mathrm{F}$. Llewellyn Jones (Swansea, Wales); a paper on the formative time-lags of uniform field breakdown by L. H. Fisher (Now York); and a paper on secondary processes and the mechanisms of spark breakdown by L. B. Loeb (California). The ensuing discussion indicated a general agreement on the role taken by the electron avalanche and the secondary ionization processes, and, while helping to clarify terminology, also indicated the field that still awaits complete quantitative explanation - as that of the complete build-up to a high current-density spark-channel after the applied voltage had attained or exceeded the static breakdown potential.

Miscellaneous subjects were dealt with in papers by C. Kenty (General Electric) on metallic flames excited by active nitrogen, by H. P. Broida (National Bureau of Standards) on afterglow of solid nitrogen, and by W. M. Brubaker (Consolidated Engineering Corp.) on space charges in mass-spectrometer ion sources. Probes for space-charge fields were discussed by P. Coopermann (Research Corporation); electronic tuning of microwave cavities by F. R. Arams and H. K. Jenny (R.C.A.) ; ionization in long nitrogen afterglows by W. B. Kunkel and A. L. Gardner (California); and studies of anode prebreakdown phenomena in thyratrons were described by S. Goldberg (Edgerton, Germeshausen and Grier, Inc.). Fire-ball discharges were discussed by $G$. Medicus (Wright Air Development Center) and by K. G. Henquist and E. O. Johnson (R.C.A.).

In closing the Conference, Dr. W. P. Allis mentioned that the general subject for the conference to be held next year will be discharge phenomena at extremely high temperatures.

F. LlewelLyN JoNes 